REVIEWS

\title{
Nurse practitioner role in home healthcare: Challenges and opportunities
}

\author{
Valencia Chicoine ${ }^{1}$, Pamela Aselton ${ }^{* 2}$ \\ ${ }^{1}$ School of Health and Natural Sciences, University of Saint Joseph Connecticut, United States \\ ${ }^{2}$ College of Nursing, University of Massachusetts, Amherst, United States
}

Received: October 16, 2014

DOI: $10.5430 /$ cns.v3n1p100
Accepted: November 19, 2014 Online Published: December 17, 2014

URL: http://dx.doi.org/10.5430/cns.v3n1p100

\begin{abstract}
Home health agencies must follow Medicare's conditions of participations, as well as federal requirements with regard to plans of care and payment. Federal laws mandate that home health agencies can not authorize nurse practitioners (NPs) to direct patient care in the home environment. Instead, all orders must be signed by a physician or Medicare reimbursement may be jeopardized. Removing this barrier to care and supporting legislation that allows nurse practitioners to write orders and manage the care of patients in home healthcare, will increase access to these services and result in more timely consults on home care cases with agencies. NPs have been shown to provide safe and effective care, and nurses have always played a major role in home care.
\end{abstract}

Key Words: Home care, Medicare rules, Nurse practitioners, Health care policy

\section{Introduction}

Nationwide health reform is attempting to address issues with our aging population due to the increased rate of chronic diseases and rising healthcare costs. The role of nursing is expanding in all areas of healthcare in the United States including decisions on health policy and the provision of home health services. ${ }^{[1-4]}$ Current federal laws that govern home health agencies do not allow nurse practitioners (NPs) to order care for homebound patients. Instead, all orders must be signed by a physician or Medicare reimbursement may be jeopardized. ${ }^{[1,5]}$ This barrier remains in contrast to the increasingly independent role NPs play in the care and management of patients in inpatient and outpatient clinical settings across the country. It has been documented that NPs provide safe and effective care that is comparable to that of physicians within homecare and other settings. ${ }^{[6,7]}$

\section{Current Medicare rules on home health- care}

Home health agencies must follow Medicare's conditions of participation, as well as federal requirements with regard to plan of care and payment. The US Code of Federal Regulations which governs home health services does not specifically address the NP's role; instead they state that a "non-physician practitioner" can provide care plan oversight only. ${ }^{[5]}$ This limits NPs from ordering medications, treatments, or discontinuing home care. Unlike many newer statutes, the statutes governing home care have not changed with recent times to expand medical practitioners other than physicians. ${ }^{[1]}$ This not only increases the cost of providing supervised home health care, it also limits care to the elderly and disabled, and can be a particular problem in rural areas where access to physicians may be limited.

*Correspondence: Pamela Aselton; Email: paselton@usj.edu; Address: College of Nursing, University of Massachusetts, Amherst, United States. 
Some physicians question letting NPs take over traditional physician roles and argue that differences in training may negatively impact overall patient care. The American Academy of Family Physicians President's position is that although they work with nurse practitioners, it should be a physician directing the team. ${ }^{[8]}$ However, multiple studies have shown that the care given by NPs and physicians within home care settings is comparable ${ }^{[6,7]}$ and the history of homecare services really started with nursing. Lillian Wald and the thousands of visiting nurses who have come after her make up the traditional workforce in homecare. ${ }^{[9,10]}$ The role of NPs in homecare writing orders seems to be affected by the perception of a threat to the financial stability of private practice physicians, not the realities of homecare. ${ }^{[4]}$

\section{Nurses' autonomy in homecare}

There are numerous barriers preventing timely care for the home heath patients that need care. In primary care settings NPs care for thousands of patients each day, and are qualified to make these determinations in home care according to the Pennsylvania Coalition of Nurse Practitioner's Susan Schrand. [11] Most nursing leaders in home care agree that advance practice nurses who care for Medicare patients need the ability to certify home health services for this population. Medicare is the insurance provider for a large portion of the U.S. population, providing benefits for the elderly and disabled US citizens. ${ }^{[12]}$ Medicare spending accounts for one-eighth of the federal budget. Research has shown that nurses and NPs offer competent, safe, patient-centered care that is affordable and accessible. ${ }^{[4]}$

Buppert $^{[1]}$ notes that NPs can conduct a home care visit, order durable medical equipment, perform a history and physical examination, order medications and treatment, and bill for the visit if using an evaluation/management current procedural terminology (CPT) code. However, the NP must be treating the beneficiary for the condition for which the item is needed, they must bill Medicare using their own provider number, and the NP must be practicing in collaboration with a physician who is signing the plan of care. Although many states have modified their laws to allow providers other than MDs to order home care, Medicare remains unchanged in not allowing payments to be certified to NPs unless signed by a physician. ${ }^{[13]}$ Under the current plan, seniors and disabled citizens that have NPs as their primary provider must see an MD they might not know in order to get home care.

\section{Initiatives for NPs in homecare}

Health care practitioners that provide home-based, primary care have the advantage of considerable time to spend with patients, a view of the patient in their home environment and more control over the services patients are receiving. ${ }^{[14]}$ Therefore, home health care is more appropriate, cost effec- tive, and beneficial for the overall health of the patients. The Centers for Medicare and Medicaid Services is beginning to realize the importance of nurse led disease management programs and have instituted several initiatives. One such initiative will provide chronically ill patients with nurse practitioner or physician led primary care services in the home setting. ${ }^{[14]}$ The Robert Wood Johnson Foundation has focused on the beneficial impact nurses have on the healthcare system. However, nurses must be allowed to practice to the full extent of their education in order to transform the way in which health care is provided.

NPs should be granted the authority to sign the plan of care, order medications, treatments, therapy, and durable equipment independently of physician collaboration or signature for home health patients. In reading the legal Medicare language, it specifies that physicians only must sign the plan of care after agreement with its contents. Our lawmakers should be educated on the expanded role NPs and nurses are already exercising in home health care situations on developing and implementing the plan of care. The physician upon its receipt, simply reads, agrees, and signs the documentation. If nurses are capable of writing the plan of care, they are also competent to write and sign orders in the expanded role of a NP!

It has been documented that NPs provide quality patient care with great disease management outcomes, as well as a discrepancy in the number of patients needing treatment and the number of physicians available to treat them. ${ }^{[4,8]}$ NPs should be able to practice without physician supervision with a collaborative relationship in homecare, the same as they are able to in other healthcare arenas. It is time for federal laws to remove the restriction on NP practice in home health care. NPs are authorized to order nursing home care for Medicare beneficiaries. However, they are unable to order the less costly home care services which does not make economic or common sense. ${ }^{[13]}$

The research showing that NPs provide safe and equitable care comparable to physicians is evidenced by the increasing number of states that have granted independent practice to NPs including: Alaska, Arizona, Colorado, Connecticut, Hawaii, Idaho, Iowa, Kentucky, Vermont, Washington, and Wyoming. ${ }^{[11]}$ These state specific practice laws allow NPs to perform the functions of primary care providers under the authority of the State Boards of Nursing. It is important to gain this acceptance and credibility on the federal level as well. ${ }^{[15]}$

In July 2012, the American College of Nurse Practitioners published a report on removing practice barriers for NPs in home care, and American Association of Retired Persons (AARP) concluded that home health costs could be greatly be reduced by allowing NPs to practice to the full extent of their licensure. The time saved by allowing NPs to order homecare services directly rather than wait for physi- 
cian sign off would allow for the more efficient provision of homecare services. Fortunately, there are policy makers who also realize the value of NPs in home healthcare. The Home Health Planning Improvement Act (HR 2267) to allow NPs to order home health care services was authored by Representatives Allyson Schwartz (D-PA) and Greg Walden (R-OR).

\section{Plan of action}

This legislation allowing NPs to sign home care orders has been rejected so far in the Congress, and nurses need to have their voice heard on this issue. This can be accomplished by supporting organizations such as the American Association of Nurse Practitioners (AANP) and by becoming active members. AANP offers advocacy and representation as well as free practice and legislative consultation, national representation in Washington, DC for the nurse practitioner profession by a government affairs office. It is also important for nursing organizations to communicate with the American Medical Association on this issue and make the case for fully independent practice for NPs in the homecare setting.

Political action may include contacting members of Congress and urging them to act upon reintroducing the Home Health Care Planning Improvement Act (H.R. 2267/S. 227) in the 213th Congress. ${ }^{[16]}$ Disseminate this information to other nursing organizations and their members asking them to contact their local policymakers requesting a change of policy. Provide testimony for NP's role in providing quality, comprehensive and effective care in the homecare environment. Support the representatives' that are promoting advocacy for NP practice and the enactment of bill HR2267. Local representatives should be contacted and asked to assist as a cosponsor. Thank legislators if they are supportive and write to your representative to ask for support. Using our collective voice to create needed changes in healthcare policy can result in more quality and affordable care for our home bound patients.

\section{References}

[1] Buppert C. Can I Order Home Health Services for PhysicianOrdered Home Healthcare? 2009. Available from: http://www. medscape.com/viewarticle/703620

[2] Bonsall K, Cheater F. What is the impact of advanced primary care nursing roles on patients, nurses and their colleagues, a literature review? Int J of Nurs Studies. 2008; 45(7): 1090-1102. PMid:17905252.

[3] Kilpatrick K. How do nurse practitioners in acute care affect perceptions of team effectiveness? J of Clinical Nurs. 2013; 22(17/18): 2636-2647. http://dx.doi.org/10.1111/jocn. 12198

[4] Wilson A, Whitaker N, Whitford D. Rising to the Challenge of Health Care Reform with Entrepreneurial and Intrapreneurial Nursing Initiatives. Online $\mathrm{J}$ of Issues in Nurs. 2012. Available from: http://www.nursingworld.org/MainMenuC ategories/ANAMarketplace/ANAPeriodicals/OJIN/T ableofContents/Vol-17-2012/No2-May-2012/Rising -to-the-Challenge-of-Ref orm.html\#Whitforddoi: 10.3912/OJIN. Vol17No02Man05

[5] Centers for Medicare \& Medicaid Services, HHS. 42 CFR 424.22-Requirements for home health services. 2010. Available from: http://www.gpo.gov/fdsys/pkg/CFR-2010-title42 -vol3/pdf/CFR-2010-title42-vol3-part424.pdf

[6] Hansen-Turton T, Ware J, Bond LD, et al. Are managed Care organizations in the United States Impeding the Delivery of primary Care by Nurse Practitioners? A 2012 Update on Managed Care organization Credentialing and Reimbursement Practices. Pop. Health Management. 2013; 116(5): 306-309. http://dx.doi.org/10. 1089/pop. 2012.0107

[7] Pirret A. Comparing NPs and Doctor's diagnostic skills. Kai Tiaki Nurs New Zealand. 2014; 20(4): 9.
[8] Pho K. How I would end the war between nurse practitioners and doctors. 2013. Available from: http://www.kevinmd.com/blog /2013/05/war-nurse-practitioners-doctors.html

[9] Buhler-Wilkerson K. Public Health Then and Now Bringing Care to the People: Lillian Wald's Legacy to Public Health Nursing. 1993. Available from: http://www.ncbi.nlm.nih.gov/pmc/a rticles/PMC1694935/pdf/amjph00536-0124.pdf

[10] Visiting Nurses Services New York - Lillian Wald. 1993; Available from: http://www.vnsny.org/community/our-history/lil lian-wald/

[11] American Association of Nurse Practitioners - State Practice Environment. 2014. Available from: http: //www. aanp.org/legislation-regulation/state-leg islation-regulation/state-practice-environment

[12] National Bureau of Economic Research - Medicare and its Impact. 2014. Available from: http://wwwdev.nber.org//digest/ap r06/w11609.html

[13] American Association of Nurse Practitioners - HR2267Ordering Home Health Care. 2014. Available from: http://www . aanp.org/legislation-regulation/news /federal-news/68-articles/332-good-news-hr2267

[14] Centers for Medicare \& Medicaid Services. Independence at Home Demonstration. 2014. Available from: http://innovation.cms .gov/initiatives/independence-at-home/

[15] Lowes R. Connecticut Becomes 18th State to Allow NP Independence. 2014. Available from: http://www.medscape.com/vie warticle/824465

[16] National Colorado Nurse Practitioner Coalition. Take Action Now: Tell Congress to Let NPs Order Home Health Services. 2013. Available from: https://ncnpc.enpnetwork. com/nurse-pra ctitioner-news/5654-take-action-now-tell-congres s-to-let-nps-order-home-health-services 